Portland State University

PDXScholar

\title{
Testing and Characterizing a Novel Sampling Method for Aerosols : Application of SPE for Oxidized Gas-Phase Compounds
}

Daniel Wright

Portland State University

Follow this and additional works at: https://pdxscholar.library.pdx.edu/honorstheses Let us know how access to this document benefits you.

\section{Recommended Citation}

Wright, Daniel, "Testing and Characterizing a Novel Sampling Method for Aerosols : Application of SPE for Oxidized Gas-Phase Compounds" (2015). University Honors Theses. Paper 125.

https://doi.org/10.15760/honors.170

This Thesis is brought to you for free and open access. It has been accepted for inclusion in University Honors Theses by an authorized administrator of PDXScholar. Please contact us if we can make this document more accessible: pdxscholar@pdx.edu. 
Testing and Characterizing a Novel Sampling Method for Aerosols: Application of SPE for Oxidized GasPhase Compounds

by

Daniel Wright

An undergraduate honors thesis submitted in partial fulfillment of the

requirements for the degree of

Bachelor of Science

in

University Honors

and

Civil Engineering

Thesis Adviser

Dr. Kelley Barsanti

Portland State University 


\section{Acknowledgements}

I would like to acknowledge, first and foremost, the major role my advisor, Dr. Kelley Barsanti, for her willingness to provide a continuous supply of guidance, feedback, and encouragement in my development of this thesis.

I would also like to express my gratitude to Dr. James Pankow for allowing me use his lab space and materials as well as Dr. Wentai Luo and Dr. Lindsay Hatch for giving me guidance with the innumerable details of lab work.

My gratitude is also extended to Craig Fairbaugh, my research partner in this endeavor, and without whom I would never have been able to be in two places at once. I would also like to thank Dr. David Wolf my University Honors Thesis advisor, for his unlimited patience. 


\section{Abstract}

The aim of this research was to develop a novel sampling method to collect volatile and semivolatile organic compounds, and particle matter, in aerosol samples. Aerosols have both biogenic and anthropogenic sources. Primary organic aerosols (POA) are directly emitted, while secondary organic aerosols (SOAs) are formed by reaction of gas-phase compounds in the atmosphere. The sampling method developed in this research will enable the collection of a complete range of compounds, with the ultimate goal of allowing regulatory agencies and scientists to improve the development and testing of computer models that predict the roles of aerosols in atmospheric and health sciences. 


\section{Introduction}

Characterization of aerosols has been a long-standing challenge in scientific disciplines from the atmospheric physics to the health sciences. Aerosols play key roles in social challenges, including acting as climate forcers and pollutants that can cause severe health impacts (EPA, 2003).

The prevalence of aerosols in many fields of research can be attributed to their capacity to form from a variety of compounds. The tendency of compounds to form aerosols is influenced by several factors, including vapor pressure, ambient temperature, and activity. These factors, as well as the diversity of compounds, can act together to complicate the characterization of aerosols. Another challenge of characterizing aerosols is determining the source of the aerosol. While there are thousands of aerosol sources, the sources can be divided into two categories: anthropogenic and biogenic. Anthropogenic aerosols are synthetic in nature (i.e., emanating from human activity); biogenic aerosols are natural in origin, but not necessarily less harmful. The variety of chemical compounds formed by the variety of different sources creates difficulty when attempting to distinguish a specific source of particle pollution. Capturing a wide range of compounds is also challenging since a single collection method is generally insufficient.

\subsection{Properties}

The chemical and physical properties of aerosols influence how it impacts the atmosphere or human health. If a compound 'harms health, environment, and causes property damage' then it is classified as a criteria pollutant and must be controlled if levels exceed national standards (EPA, 2014). Aerosols are composed of primary organic aerosols (POAs), which are aerosols that are directly emitted, or secondary organic aerosols (SOAs), aerosols formed in the atmosphere 
through physical and chemical interactions. One example of SOA is the condensation of sulfur dioxide into liquid particles to form sulfates (Masters, 1998).

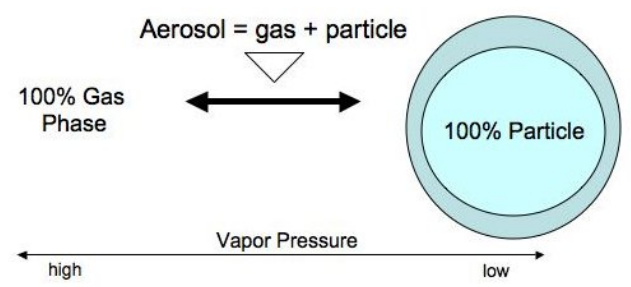

Figure 1: The role of vapor pressure in aerosol formation

Aerosols have particle, solid or liquid, and gas phases (Error! Reference source not

found.Error! Reference source not found.Figure 2). Each phase is considered a separate environmental compartment and compounds may move between compartments due to environmental influences, thus changing the composition of the aerosol. 
The variables that govern the behavior of a compound in an aerosol (i.e., partitioning between the gas- and particle-phase) are related by the equation for the partitioning coefficient, $K_{\mathrm{p}, \mathrm{i}}$ (Figure 2:Pankow 1996). The partitioning coefficient describes the amount of the compound ( $F$ in units of $\mu \mathrm{g} / \mathrm{m}^{3}$ ) that is in the particle phase (PM), versus the amount of the compound that is in the gas phase ( $A$ in units of $\mu \mathrm{g} / \mathrm{m}^{3}$ ) (Pankow, 2012). Some variables, such as liquid vapor pressure, have a greater influence than others, such as activity. Weight fraction of adsorptive particle matter $\left(f_{\mathrm{om}}\right)$, mean molecular weight $\left(\mathrm{MW}_{\mathrm{om}}\right)$, and activity $\left(\zeta_{\mathrm{i}}\right)$, will not be discussed (for complete list of variables see Figure 2 caption).

$$
K_{\mathrm{p}, i}=\frac{c_{\mathrm{p}, i}(\mu \mathrm{g} / \mu \mathrm{g})}{c_{\mathrm{g}, i}\left(\mu \mathrm{g} / \mathrm{m}^{3}\right)}=\frac{F_{i} / \mathrm{PM}}{A_{i}}=\frac{f_{\mathrm{om}} R T}{10^{6} \overline{\mathrm{MW}}_{\mathrm{om}} \zeta_{i} p_{\mathrm{L}, i}^{\mathrm{o}}}
$$

Figure 2: Partitioning coefficient as function of liquid vapor pressure, temperature, activity, weight fraction, and mean molecular weight; $R$ is the ideal gas constant.

The liquid vapor pressure $\left(p_{\mathrm{Li}}^{\mathrm{o}}\right)$ is a measure of compound volatility. Volatility is the most influential variable in determining the $K_{\mathrm{p}}$ values. This makes determining the volatility of a compound necessary for establishing the partitioning behavior and resultant aerosol formation. Volatile organic compounds (VOCs) are compounds with a low carbon number, usually C3 to C25, that exist in the gas phase (Tro, 2013). Semi-volatile organic compounds (SVOCs) are distributed between the gas and particle phase; compounds with the lowest volatilities will have the highest concentrations in the particle phase (Figure 1). While aerosols have two distinguishable phases (gas and particle), volatility is a relative definition that is based on the compounds and conditions in the mixture of interest.

\subsection{Climate Change and Air Pollution}


The role of aerosols in climate change is divided into direct and indirect effects. The reflection of sunlight by aerosols is defined as a direct effect since the particulate phase of the aerosol is physically reflecting the light, whereas the influence of the particulate phase on cloud formation and lifetime is defined as a secondary effect (Masters, 1998). Aerosols differ from greenhouse gases in that their lifespan is on the order of days and years, while greenhouse gases can last for decades; however aerosols can have strong regional effects on climate (Voiland, 2010).

The National Ambient Air Quality Standards (NAAQS) define the acceptable concentrations of pollutants in the atmosphere based on the impacts those pollutants can have at established concentrations for a time duration of exposure. The particulate phase of aerosols is also known as particle matter (PM). PM is divided into two categories, $\mathrm{PM}_{2.5}$ and $\mathrm{PM}_{10}$; particles with diameters of $\leq 2.5$ microns or $\leq 10$ microns in diameter respectively. The standards for $\mathrm{PM}_{10}$ and $\mathrm{PM}_{2.5}$, common pollutants, is set at a 24 hour maximum concentration of 150 and $35\left(\mu \mathrm{g} / \mathrm{m}^{3}\right)$, respectively, and can result in reduced visibility as well as excess deaths (U.S. EPA, 1994). Models used to enforce these standards and predict effects of pollutants require data for validation and continued development. Data are obtained by collecting and analyzing aerosol samples; the analysis details the composition of the aerosol sample retained on the collection media. The composition of aerosols then can be used to assist in determining sources.

\subsection{Sampling}

Without effective means of analyzing samples for their specific chemical constituents, regulatory agencies lack sufficient information to determine the effects aerosols from specific sources are having on the atmosphere or on human health. The potential positive application of aerosols for 
geoengineering and climate control also requires the ability to understand the existing composition of atmospheric aerosols.

A single simple method of collecting and analyzing aerosols is a challenge due to the variable nature of aerosols, as previously discussed in Section 1.1. Many current collection methods focus specifically on a specific class or range of compounds, such as VOCs or SVOCs. An apparatus capable of capturing VOCs and SVOCs, as well as PM, would provide a wealth of information; this information could then be integrated into pollutant models. This research will examine the ability to combine analysis methods as well as introduce the use of SPE for aerosol collection in a portable apparatus capable of collecting compounds with a range of volatilities as well as particle matter.

\section{Literature Review}

Ligocki and Pankow (1985) conducted some of the earlier research in aerosol collection and analysis. Their research lays out the usage of a dual method for collecting and analysing compounds with a range of volatility from tricholoethene to coronene during rain events (Figure 3).
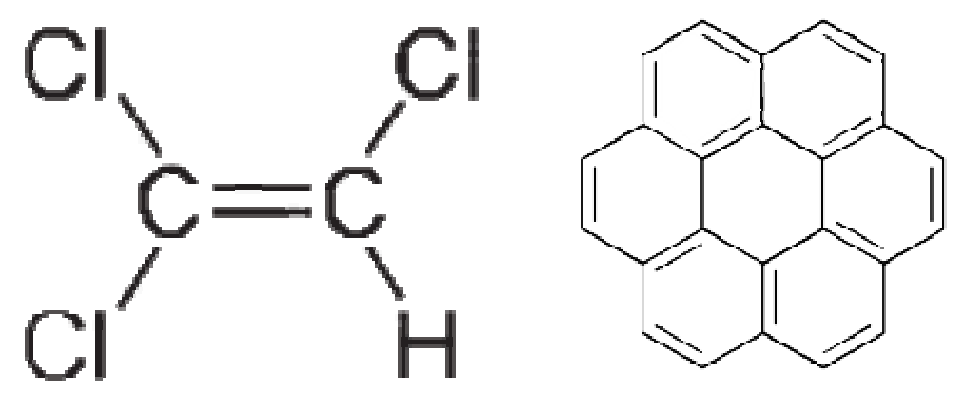

Figure 3: Trichloroethene (left) and Coronene (right) 
This research was conducted when one of the main challenges was the ability to collect samples reliably and at a scale that produces a test volume large enough to run analysis. Their setup provides a fundamental arrangement for aerosol collection systems. In this work, polyurethanefoam plugs (PUFPs) are replaced by solid phase extraction (SPE) filters (Ligocki and Pankow, 1985).

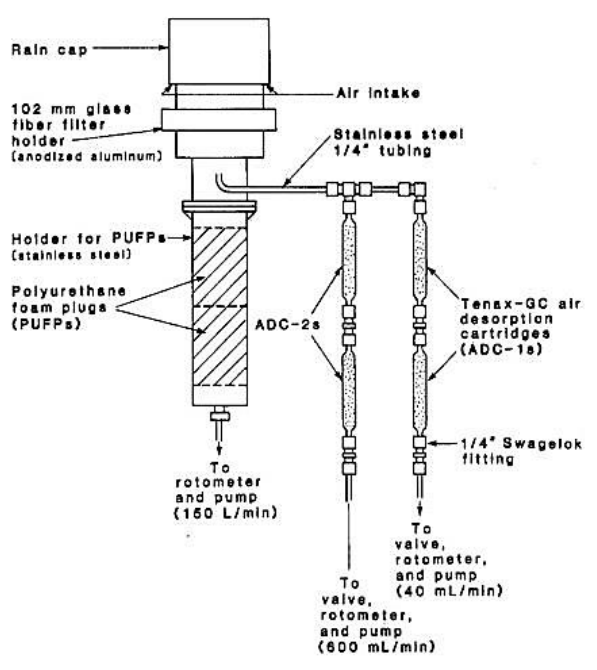

Figure 4: Ligocki and Pankow Apparatus using Polyurethane Foam Plugs and Tenax- GC ADC cartridges

Staaf and Ostman's article details the procedure for streamlining the solid phase extraction (SPE) process used by other researchers (2005). SPE cartridges are preferrable to other collection filters, such as PUFPS, because the cartridges can be used for both sampling and extraction. This combination of steps allows for the removal of time-consuming manual steps and can be used with both gas chromatography and mass spectrometry analysis. Extraction of the filters used methyl-tert-butyl ether with recovery rates of roughly $100 \%$. 
The role of decomposition of compounds on the sampling medium itself has encouraged faster derivitization techniques; on such technique is online derivitization. Recently, Issacman et al. (2014) explored the use of online derivitization with an automated in-situ apparatus to improve the number of compounds that can be resolved in semi-volatile thermal desorption aerosol gas chromatography (SV-TAG). SV-TAG allows the collection of particle only samples and particle-plus-vapor combined samples by using a dual cell. These sampling apparatuses are often large and require stationary sampling.

\section{Goals and Objectives}

Our research will evaluate the feasibility of using Polytetraflouroethylene (PTFE) filters, Adsorption Thermal Desorption (ATD) cartridges, and SPE filters to capture compounds ranging from volatiles to semi-volatiles and particle matter. This study is taking place in two phases. The first phase evaluated the effectiveness of using SPE independently. Phase two will assess the ability of SPE and ATD to be used to collect VOCs and SVOCs simultaneously.

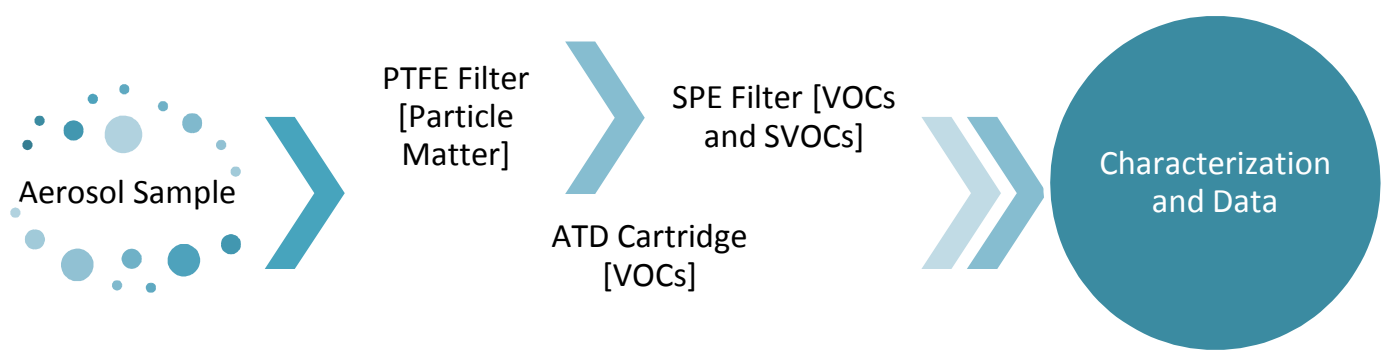

Figure 5: Collection Range of Compounds for Individual Components of Sampler

\subsection{Phase I}


A novel sampling method was tested in phase one of this research. This method used two SPE filters in series to collect aerosol samples, which were then extracted to characterize the SVOCs captured on the filters. The breakthrough found in a filter was quantified as the mass difference between filters. This allowed us to estimate the rate of retention of each filter based on the mass loading (Table 1).

Characterization of compounds retained on the SPE filters is taking place at EMSL using gas chromatography with mass spectrometry (GC-MS). The chromatographs produced from this analysis will be used to determine the range of compounds retained on the filters.

\subsection{Phase II}

In phase two an ATD cartridge will be placed in parallel with an SPE filter. A PTFE filter will be placed upstream of the SPE filter to capture particle matter for analysis and to prevent contamination of the SPE filters in the SVOC line. The SPE filter will collect compounds with lower volatility than collected by the ATD cartridges, but higher volatility than collected by the PTFE filters.

\section{Methodology}

\subsection{Apparatus Design}

The SPE filters were prepared with a $5 \times 5 \mathrm{ml}$ rinse of acetone and methanol to remove contaminants. Filters were dried in a heated glass cylinder with a constant low-flow supply of nitrogen. Each filter was then pre-weighed and placed in a clean foil packet.

Foil pieces and packets were sterilized by baking for 12 hours in a $160^{\circ} \mathrm{F}$ oven. The sampling apparatus for phase I was constructed using two Teflon filter holders, 1/4" Teflon tubing, five 1/4" plastic ferrules, and one valve. Teflon tubing, ferrules, and valve were sonicated three 
times for 15 minutes each in an acetone bath then wrapped in sterile foil and dried via evaporation in a fume hood.

ATD cartridges will be used for the collection of VOCs. An ozone and PM filter will be placed upstream in the sampling line. This filter will prevent fouling with PM from the samples. Removing ozone from the sample is a necessity to prevent on-filter decomposition due to reaction of sampled compounds with ozone to form secondary products. Selection of pumps to pull air through will be dictated by the sample volumes required by each component, approximately three $\mathrm{L} \mathrm{min}^{-1}$. A flowmeter was calibrated for high and low flow using compressed nitrogen gas and a digital flow meter. Once samples from phase II are collected they will be prepared for shipment and sent for analysis at the Environmental and Molecular Sciences Laboratory (EMSL) at the Pacific Northwest National Laboratory (PNNL). 


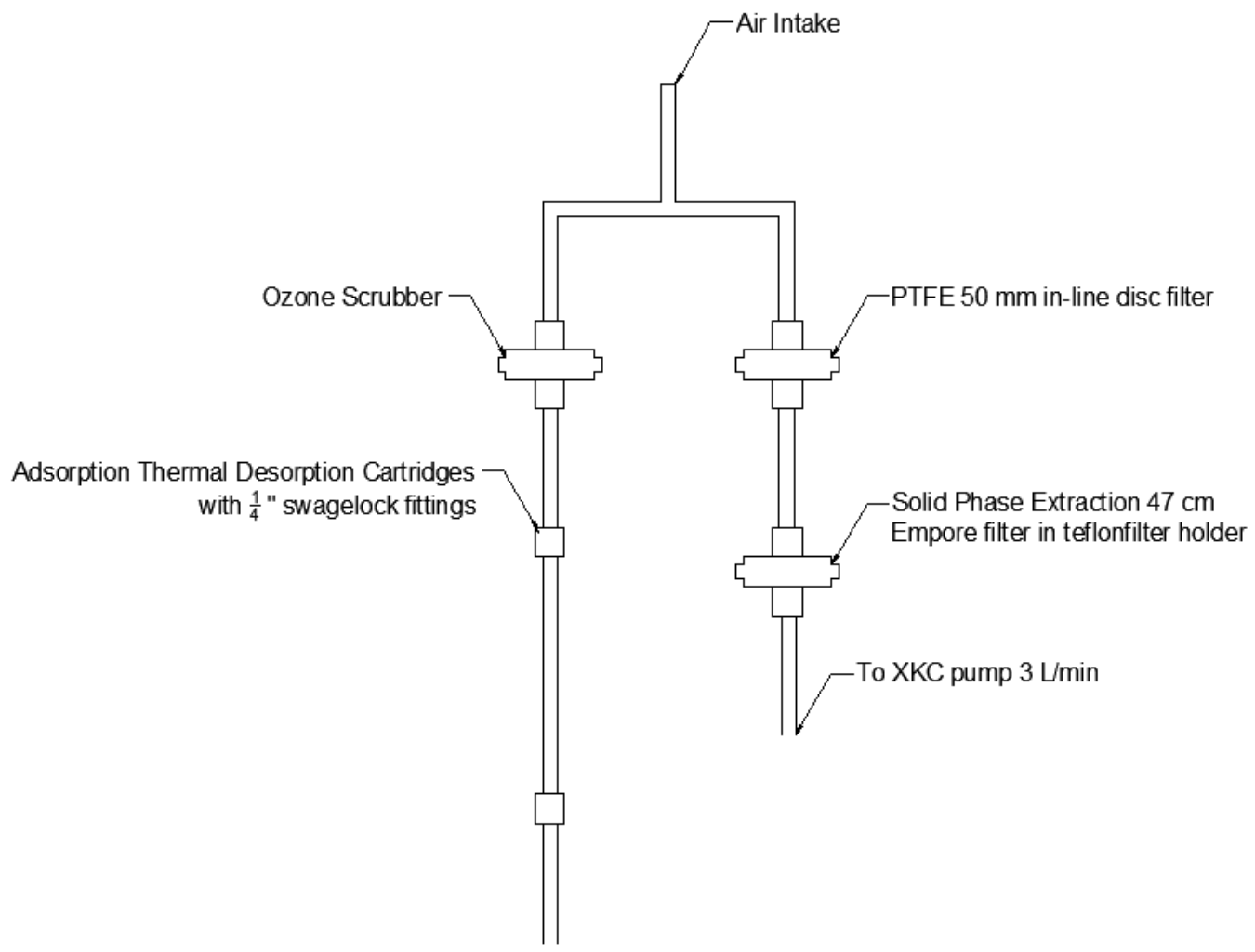

Figure 6: Apparatus Diagram for SPE filter, ATD cartridge, and PTFE filter for collecting volatile, SVOC, and particle matter in aerosol sample

\subsection{Sampling Approach}

Collected samples were stored in a refrigerator at below freezing. Samples from phase I were shipped with dry ice to PNNL, in Richland, Washington. Compounds from the ATD cartridges will be extracted using thermal desorption and injected via carrier gas for analysis using twodimensional gas chromatography (GC x GC). The SPE and PTFE filters will be extracted at EMSL. This extract will be split with one half being derivatized for use with GC $x$ GC at PSU and one half being analyzed with LC x LC at EMSL. 
SPE filters were placed in the apparatus in the lab and two Natural American Spirit cigarettes were sampled utilizing the ISO 3308-2012 smoking procedure. Sampled filters were then removed from the apparatus and placed in sterilized aluminum packets. A second round of sampling followed with new samples being removed from sterile packets and placed in the apparatus filter holders. A blank filter was brought out and held in the same sampling area before also being placed in a sterile packet. These packets were then weighed with the filters in them to determine the collected mass (Table 1)

\subsection{Chromatograph Interpretation}

PTFE filters were tested at Reed College and analysis was performed by EMSL which produced chromatographs (Appendix A). These chromatographs display the species distribution on the filters based on deviations from the blank, indicated by a red line. The mass to charge ratio on the horizontal axis can be related to volatility based on the elution of the sample. As the sample is heated the most volatile compounds elute first followed by the less volatile compounds with higher masses. These results confirmed the feasibility of using SPE filters in series with ATD cartridges to collect aerosols across a range of volatilities.

\section{Application and Conclusions}

\subsection{Results}

\subsubsection{Phase 1: Results}

In phase one of the research, our apparatus has shown itself to effectively collect SVOCs using solid phase extraction filters (SPE).

\subsubsection{Phase II Planning}


In phase two, the ability of our apparatus to collect VOCs using adsorption-thermal desorption (ATD) cartridges in conjunction with SPE filters will be assessed. This research will be performed at EMSL labs in June and July of this summer.

\subsection{Conclusion}

Our apparatus combines a wide range of analysis capability with an easily implemented setup. Unlike many setups, which require large stationary arrangements, ours can be mobilized due to the low weight, autonomy, and simple assembly (Figure 6). Power requirements consist of only two XKC pumps for the two separate sample lines. Filters and cartridges can be exchanged easily between rounds of sampling.

Initial results of the SPE assessment showed a significant retention of approximately $80 \%$ by mass on the first filter based on pre- and post-weight data. Samples were sent to PNNL for analysis to derive chromatographs. This research will continue into Phase II this summer with analysis of ATD and SPE collection in parallel (Figure 11: Apparatus Layout for sampling of VOCs, SVOCs, and PM

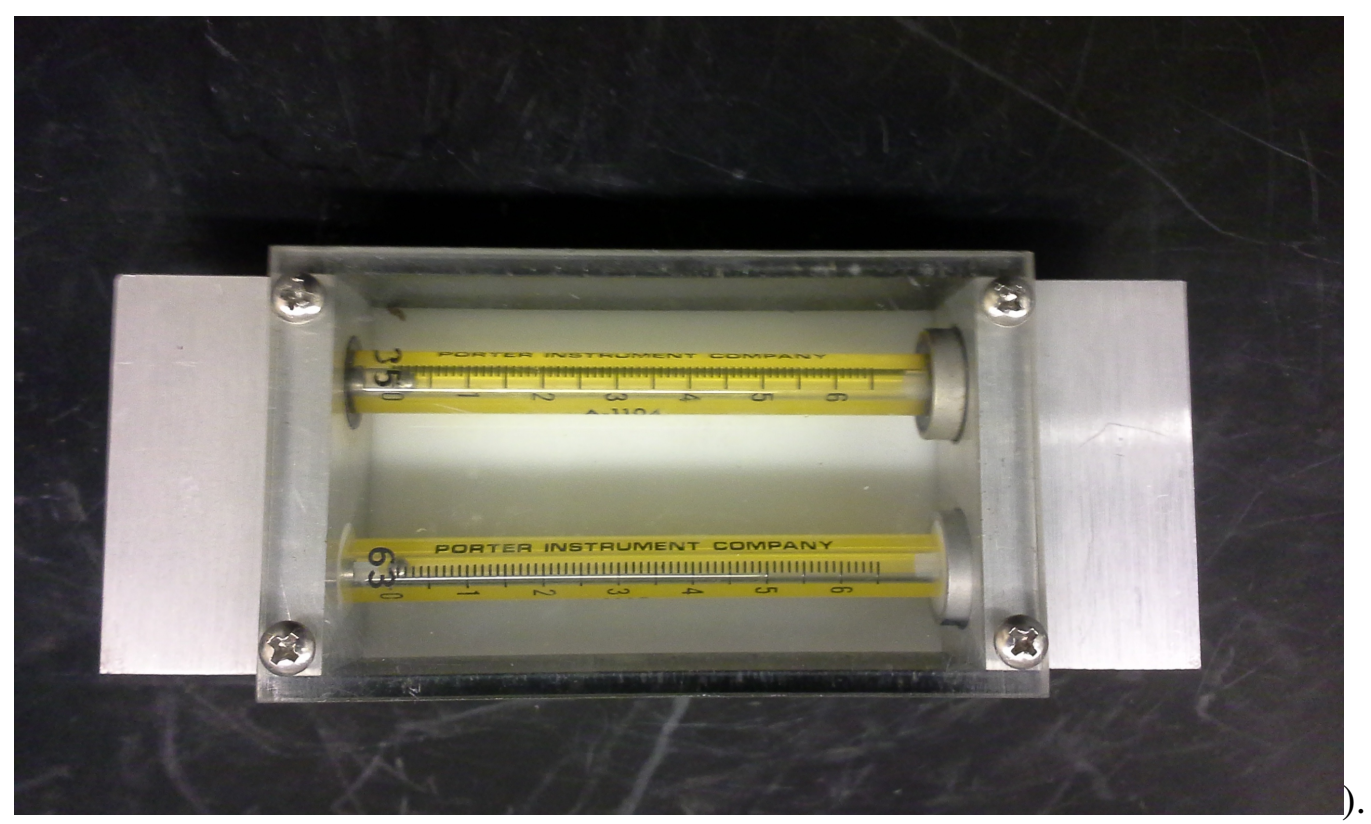




\section{Citations:}

\section{Figures:}

Figure 1: The role of vapor pressure in aerosol formationError! Reference source not found., Scripps Institute of Oceanography, UC San Diego

Figure 2: Partitioning coefficient, James Pankow, AAAR Tutorial

Figure 3: Trichloroethene (left) and Coronene (right)

Figure 6: Apparatus DiagramFigure 4: Ligocki and Pankow Apparatus using Polyurethane Foam Plugs and Tenax- GC ADC cartridges

Figure 5: Collection Range of Compounds for Individual Components of Sampler

Figure 6: Apparatus Diagram for SPE filter, ATD cartridge, and PTFE filter for collecting volatile, SVOC, and particle matter in aerosol sample

\section{References:}

Tro, Nivaldo J. (2013). Chemistry: A Molecular Approach $3^{\text {rd }}$ ed. New Jersey: Prentice Hall,

Masters, Gilbert M. (1998). Introduction to Environmental Engineering and Science $2^{\text {nd }}$ ed. New Jersey: Prentice Hall.

Voiland, A (2010). Aerosols: Tiny Particles, Big Impact. National Aeronautics and Space Administration: Earth Observatory. Web. http://earthobservatory.nasa.gov/Features/Aerosols/page1.php

Office of Air and Radiation (2003). Particle Pollution and Your Health: Environmental Protection Agency

Ligocki, M. P., \& Pankow, J. F. (1985). Assessment of adsorption/solvent extraction with polyurethane foam and adsoption/thermal desorption with Tenax-GC for the collection and analysis of ambient organic vapors. Analytical Chemistry, 57(17), 1138-1144.

Staaf, T., \& Ostman, C. (2005). Indoor air sampling of organophosphate triesters using solid phase extraction (SPE) adsorbents. Journal of Environmental Monitoring $\square:$ JEM, 7, 344-348. doi:10.1039/b411975d 
Kallio, M., Kivilompolo, M., Varjo, S., Jussila, M., \& Hyötyläinen, T. (2008). Data analysis programs for comprehensive two-dimensional chromatography. Journal of Chromatography A, 1216, 2923-2927. doi:10.1016/j.chroma.2008.11.037

Isaacman, G., Kreisberg, N. M., Yee, L. D., Worton, D. R., \& Arthur, W. H. (2014). On-line derivatization for hourly measurements of gas- and particle-phase semi-volatile oxygenated organic compounds by Thermal desorption Aerosol Gas chromatography ( SV-TAG ), 1-28. doi:10.5194/amt-7-4417-2014 


\section{Appendix A: EMSL Chromatographs}

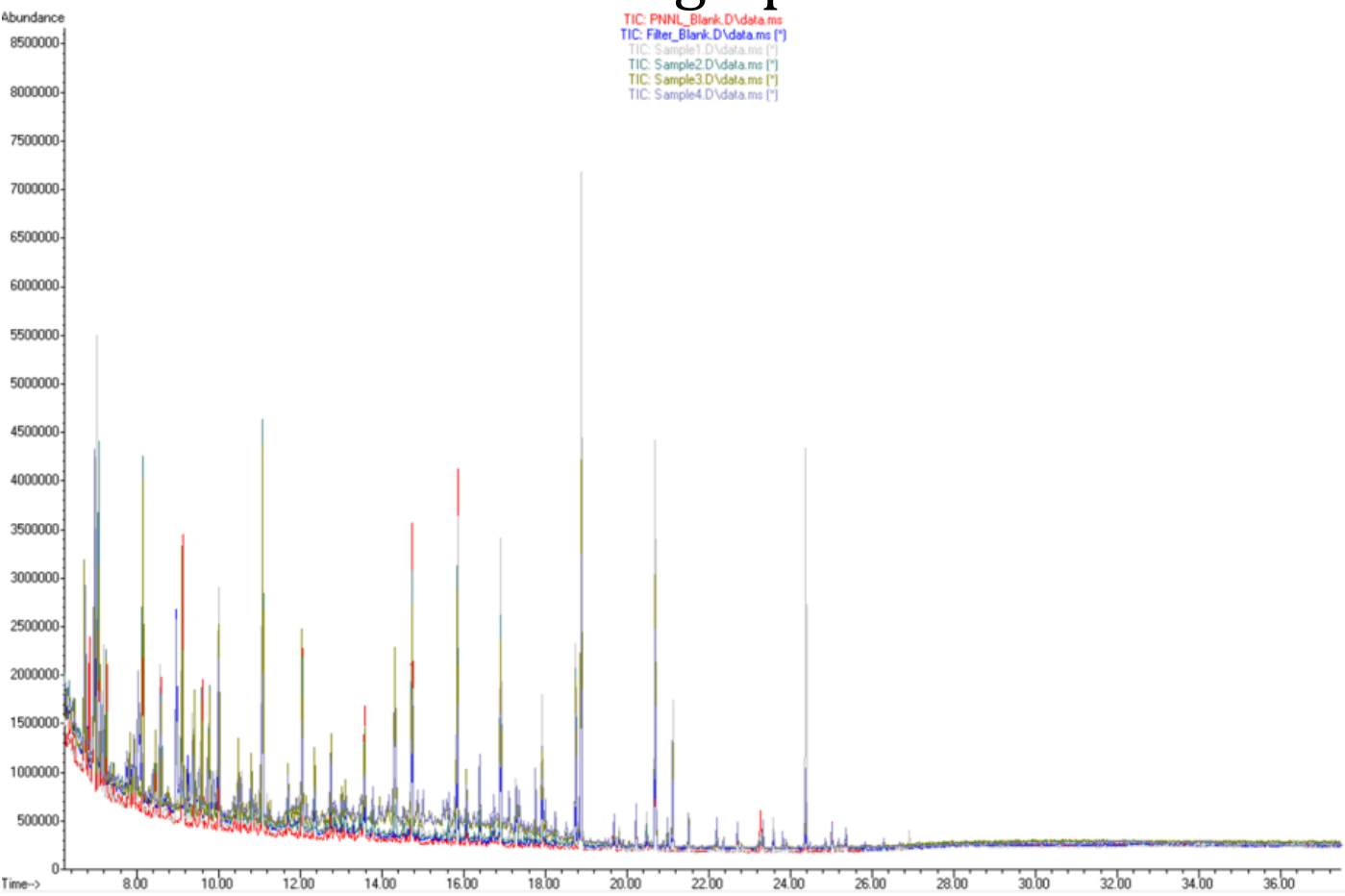

Figure 7: Overall Chromatograph

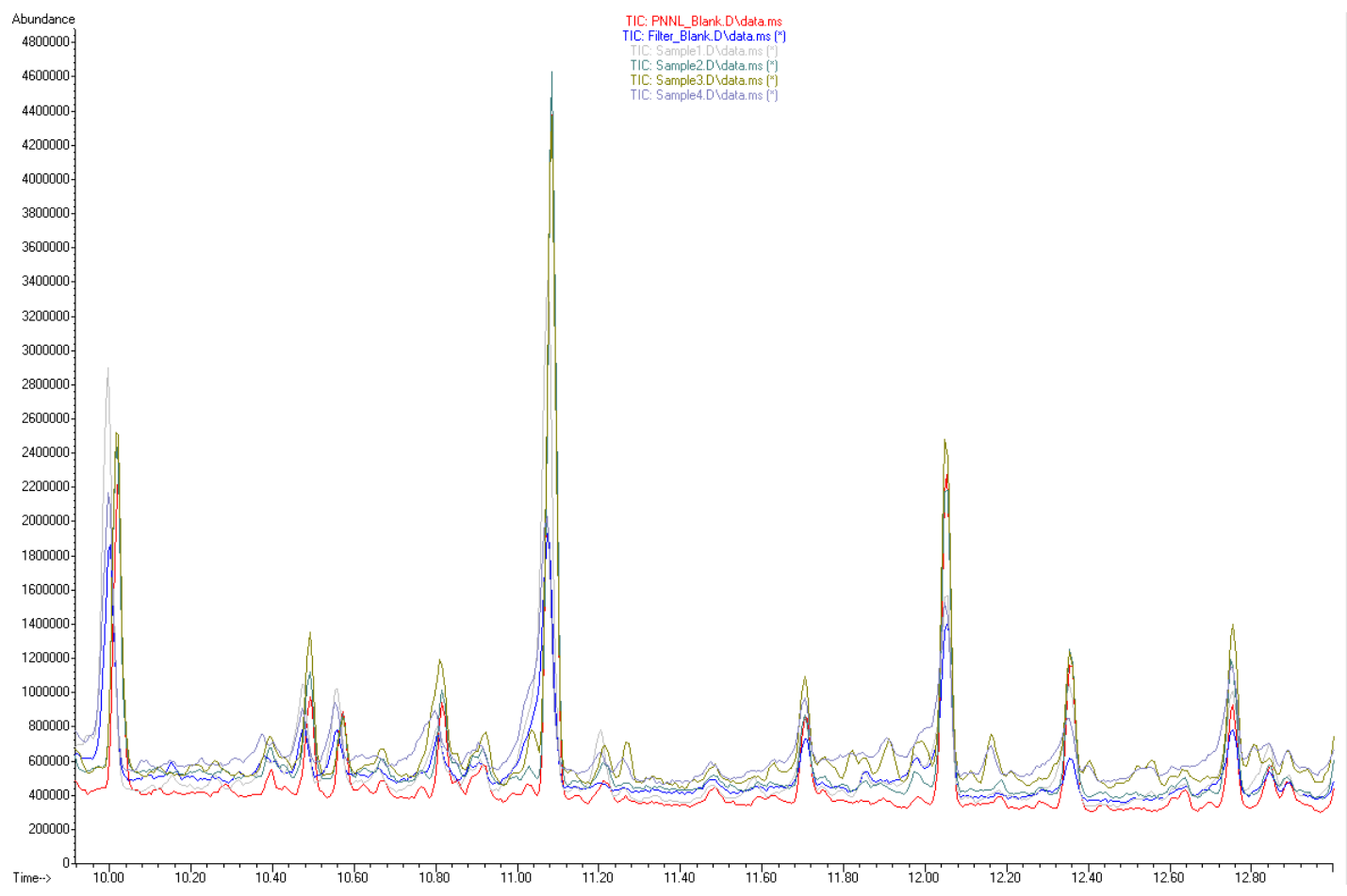

Figure 8: Chromatograph from 10 to 13 minutes 


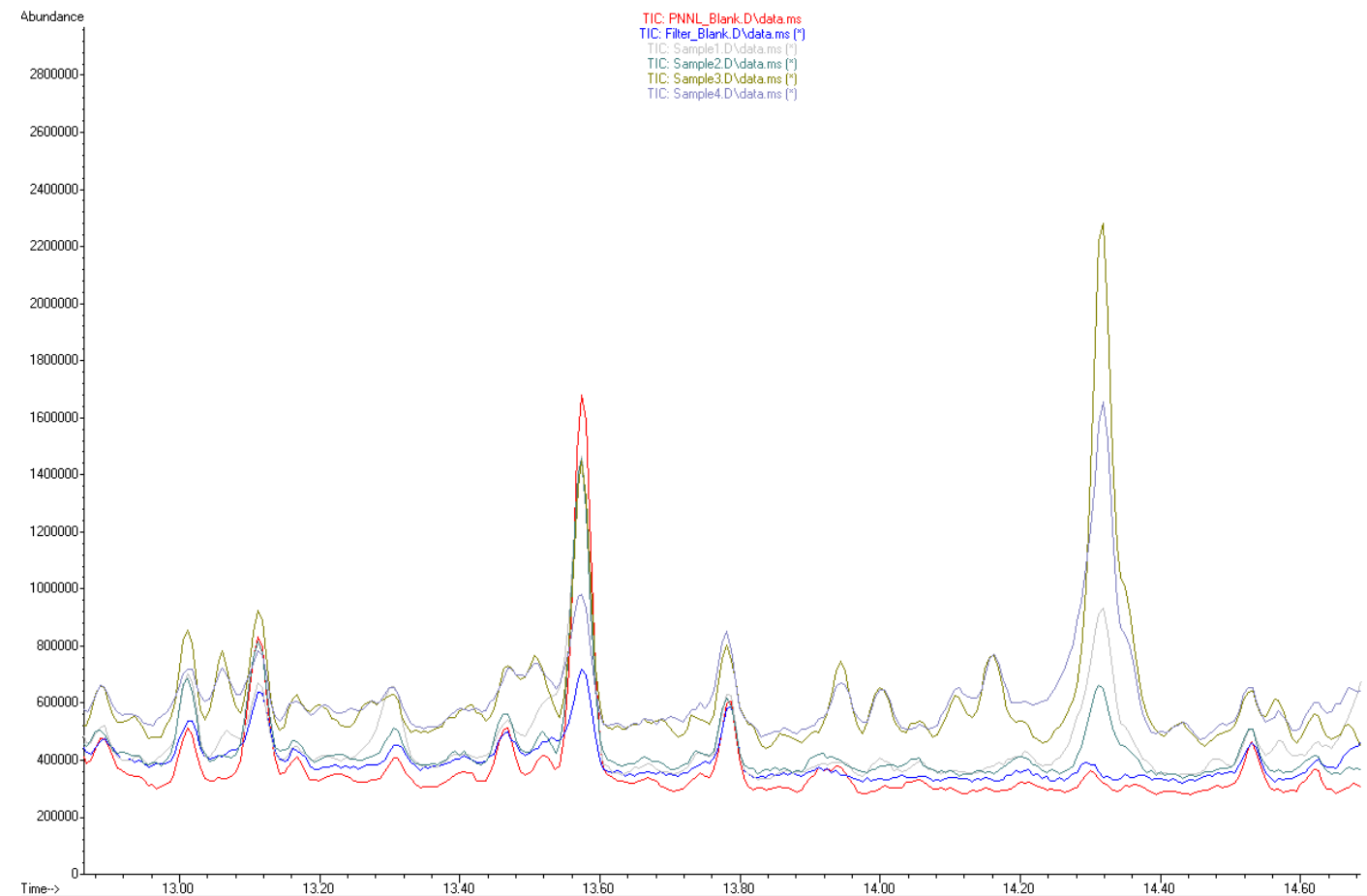

Figure 9: Chromatographs from 13 to 15 minutes

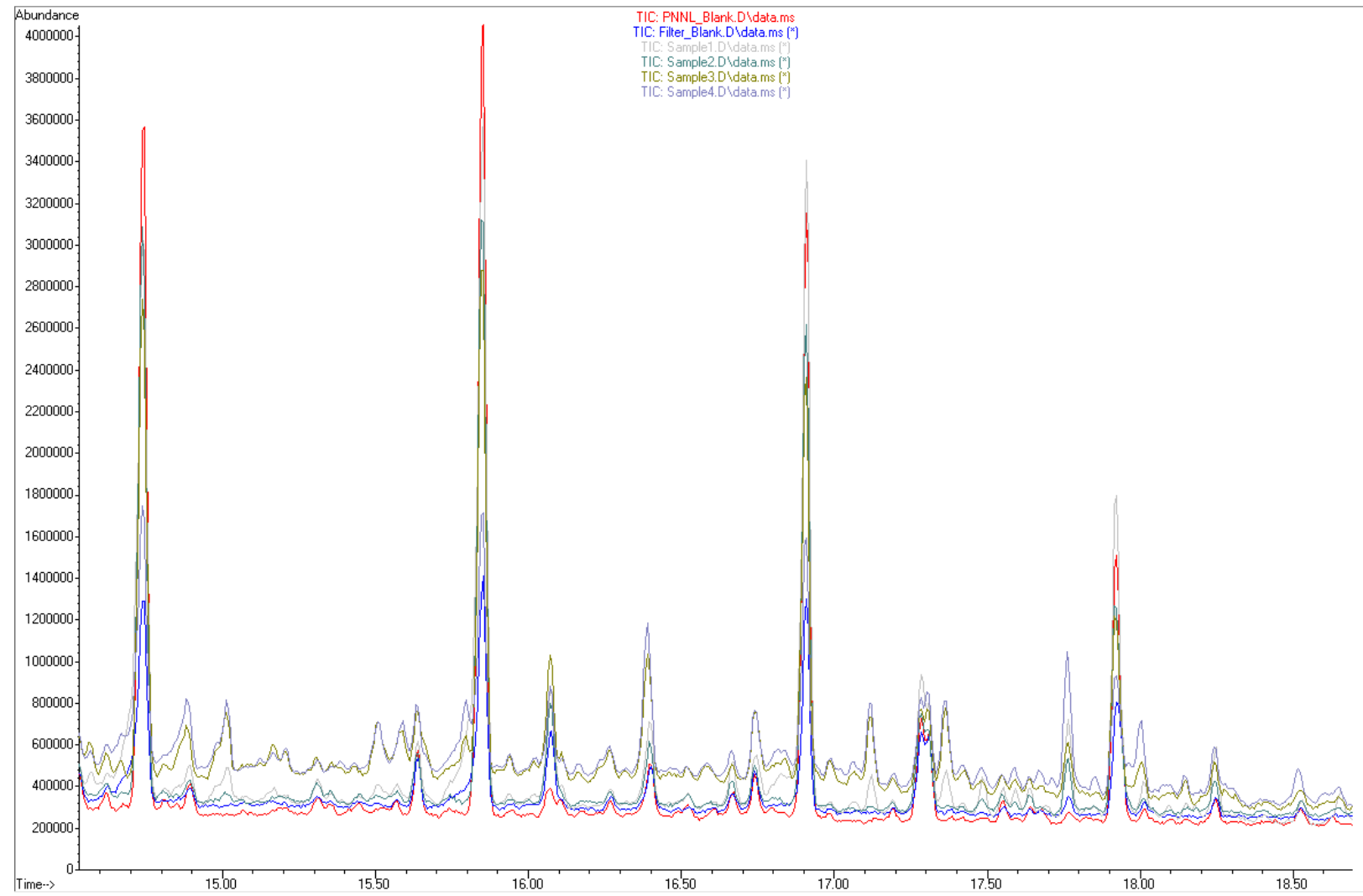

Figure 10: Chromatograph from 13 to 19 minutes 


\section{Appendix B: Apparatus Photographs}

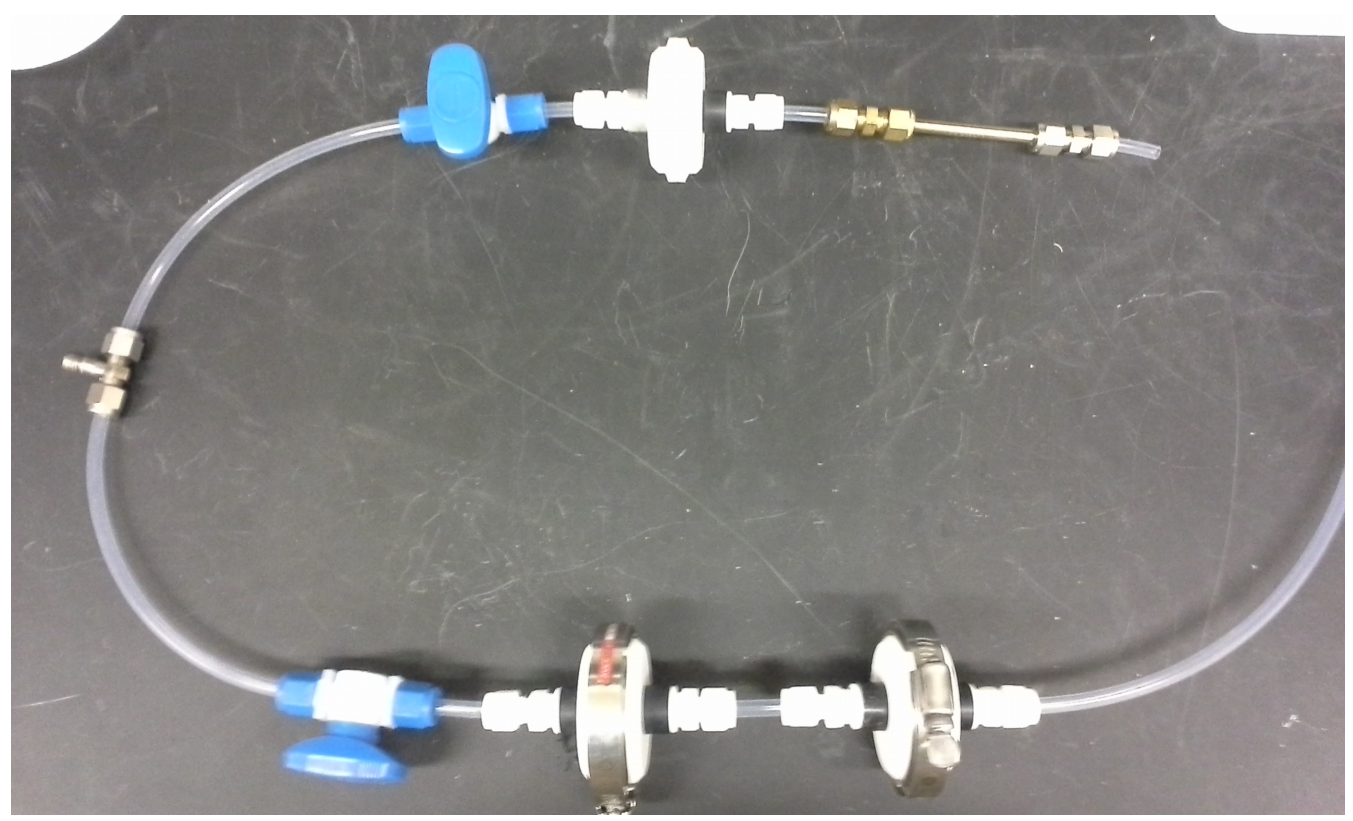

Figure 11: Apparatus Layout for sampling of VOCs, SVOCs, and PM

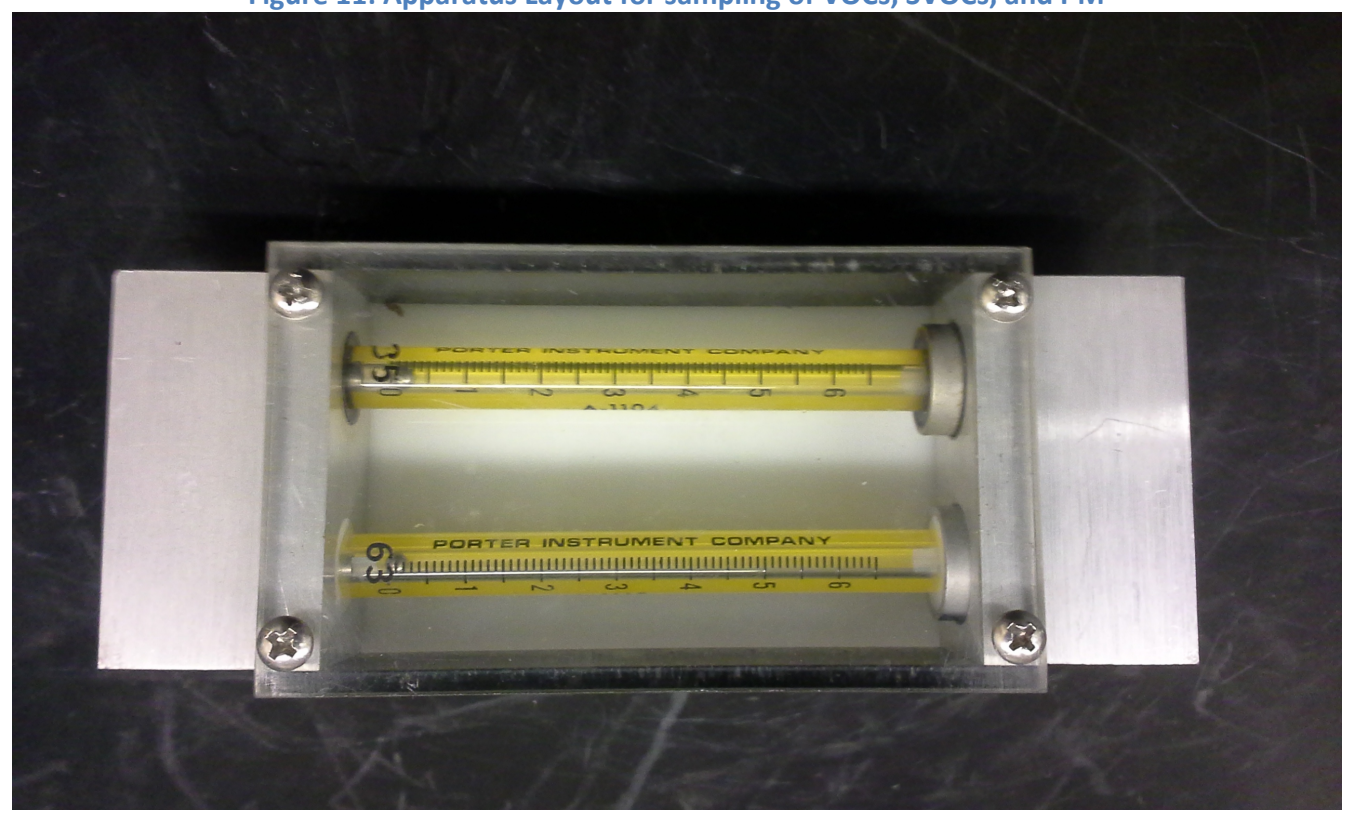

Figure 12: Flowmeter for Use with Sampler 


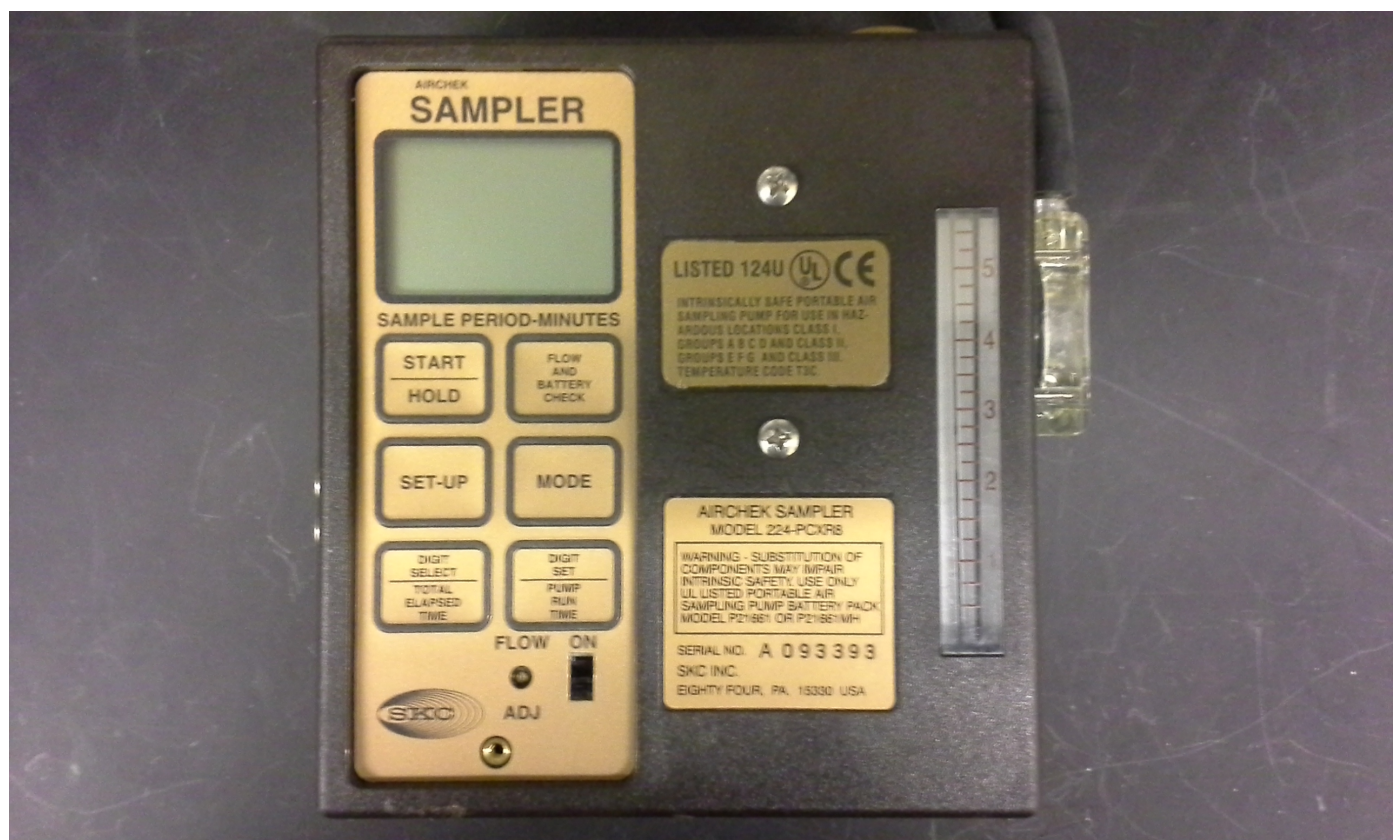

Figure 13: SKC Universal Sample Pump for use with sampler 


\section{Appendix C: Phase I Data}

Table 1: Mass sample Data and Percent Retained per Filter for Phase I

\begin{tabular}{|c|c|c|c|c|c|}
\hline & & Preweigh & Postweigh & Mass Retained ( $\mu \mathrm{g})$ & Percent Retained per Filter \\
\hline Blank & & 617.67 & & 0 & \\
\hline \multirow[b]{2}{*}{ First Run } & first chamber & 616.36 & 623 & 6.64 & 87 \\
\hline & $\begin{array}{l}\text { second } \\
\text { chamber }\end{array}$ & 600.32 & 601.3 & 0.98 & 13 \\
\hline \multirow[b]{2}{*}{ Second Run } & first chamber & 598.8 & 601.4 & 2.6 & 74 \\
\hline & $\begin{array}{l}\text { second } \\
\text { chamber }\end{array}$ & 604.1 & 605 & 0.9 & 26 \\
\hline
\end{tabular}

